\title{
Student's Online Learning Readiness In Times Of Covid-19: Self-Report Of Undergraduate Psychology Students In Portugal
}

\author{
Marisa Simões Carvalho, MSC, and Simões \\ Carvalho* \\ Universidade Católica Portuguesa, Faculty of Education \\ and Psychology, Research Centre for Human \\ Development, Portugal \\ mscarvalho@porto.ucp.pt
}

Student's Online Learning Readiness in times of Covid-19

\begin{abstract}
In times such as these of world pandemic where the spread of COVID-19 has resulted in the shutdown of schools and universities for face-to-face learning activities, the use of digital technology was intensified. The online learning environment is different to the regular classroom environment. Technology may offer multiple opportunities for learning and diverse means for teaching. The use of technological solutions to enable the continuity of learning from home raised challenges to continue effective teaching-learning processes. Considering online learning, some dimensions have been identified as relevant for learning to occur and be effective. Students' readiness for online learning is one of these dimensions. This brief study aimed to measure undergraduate Psychology students' online learning readiness at a Portuguese university. Participants exhibited above-medium levels of readiness toward online learning and presented highest readiness in the subscale of technical skills, followed by communication competencies, and the lowest readiness in the subscales related to social competencies both with classmates and the instructor/teacher. From these results, we can derive implications for teaching practice.
\end{abstract}

\section{CCS CONCEPTS}

-Social and professional topics; • Professional topics; • Computing education; • Computing literacy;

\section{KEYWORDS}

Online learning, Students' readiness, Teaching, University

\section{ACM Reference Format:}

Marisa Simões Carvalho, MSC, and Simões Carvalho and Rosário Serrão Cunha, RSC, and Serrão Cunha. 2020. Student's Online Learning Readiness In Times Of Covid-19: Self-Report Of Undergraduate Psychology Students In Portugal: Student's Online Learning Readiness in times of Covid-19. In 9th International Conference on Software Development and Technologies for Enhancing Accessibility and Fighting Info-exclusion (DSAI 2020), December

\section{${ }^{*}$ corresponding author}

Permission to make digital or hard copies of part or all of this work for personal or classroom use is granted without fee provided that copies are not made or distributed for profit or commercial advantage and that copies bear this notice and the full citation on the first page. Copyrights for third-party components of this work must be honored.

For all other uses, contact the owner/author(s).

DSAI 2020, December 02-04, 2020, Online, Portugal

(C) 2020 Copyright held by the owner/author(s).

ACM ISBN 978-1-4503-8937-2/20/12.

https://doi.org/10.1145/3439231.3440609

\author{
Rosário Serrão Cunha, RSC, and Serrão Cunha \\ Universidade Católica Portuguesa, Faculty of Education \\ and Psychology, Research Centre for Human \\ Development, Portugal \\ rscunha@porto.ucp.pt
}

02-04, 2020, Online, Portugal. ACM, New York, NY, USA, 4 pages. https: //doi.org/10.1145/3439231.3440609

\section{INTRODUCTION}

In times such as these of world pandemic where the spread of COVID-19 has resulted in the shutdown of schools and universities for face-to-face learning activities, the use of digital technology was intensified. In Portugal, such in other countries, several higher education institutions closed their campuses. Classroom classes were suspended, as well as live student tutorial support, and activities started being developed via the internet [1].

At the same time, the use of technological solutions to enable the continuity of learning from home raised challenges to continue effective teaching-learning processes, mostly with disadvantaged groups of students such as those with special needs. As most schools and teachers were not used to online teaching [2], immediate change was a challenging process [3]. Despite the availability of technologic resources, teachers' qualifications, and school practices for using digital devices effectively needed and need to improve [4]. Other difficulties and challenges were identified such as students lack of access to relevant technology and internet, different modes for academic activities supplies (e.g., additional tasks and excessive homework), and limited opportunities for deeper explanations from teachers when required [5]. These kinds of measures had several consequences, including higher levels of stress for students and families [5]. Changing from face-to-face to online/distance learning was not only a matter of providing access to technology and open learning resources, but also required maintaining effective teaching practices and social relationships between families, teachers and students, particularly for those students who lack the resilience, self-directed learning strategies, learning self-regulation, or engagement to learn on their own [4].

The online learning environment is different to the regular classroom environment $[6,7]$. Technology may offer multiple opportunities for learning and diverse means for teaching. However, this use of technology asks for adapted answers to what people learn, how people learn, where people learn and when they learn. In that sense, "distance learning should not forget how learning happens" [8] (p. 106390), which may represent an enhanced need for a shift from the traditional, teacher-centered, and lecture-based activities towards a more student-centered teaching-learning process, with activities including group, discussions, hands-on learning activities, and limited use of traditional lectures [6, 7, 9]. 
Considering online learning, some dimensions have been identified as relevant for learning to occur and be effective. Social presence and teacher presence are two relevant elements that are mentioned in the literature [6]. One other important dimension is students' readiness for online learning since previous research has supported the positive relationship between students' readiness and students' academic achievement in online learning (Kerr et al., 2006, cit in. [10]). With the transition to online classes in universities, these dimensions must be considered by teachers, schools, universities, as well as students. Specifically, students' readiness for online learning is pre-requisite for learning that must be accounted when planning engaging and effective lessons. Online readiness has gathered different definitions along the years of research, yet in general terms it means to be both mentally and physically ready for activities, experiences and actions that occur in the online learning environment (Borotis \& Poulymenakou, 2004, cit in. [11]).

To better understand how to achieve effective online learning, it is necessary to know what dimensions of online learning readiness college students should possess and reflect about its implications for teaching and learning. Yu and Richardson [12] proposed a conceptual model for students' readiness in online learning (Student Online Learning Readiness - SOLR) which consists of four components that are related with learning outcomes and learner satisfaction in online learning environments. These components are: (i) social competencies with the instructor/teacher; (ii) communication competencies, (iii) social competencies with classmates; and (iv) technical competencies. The positive relationships between the four components of the SOLR model and learning outcomes/learner satisfaction in an online learning environment have been verified in previous research [10]. Since students' online learning readiness plays a significant role in learning, it is useful to explore its core dimensions and relations in higher education. This study is an attempt to gather data on students' perception of their own online learning readiness in a higher education context and derive implications for distance and online learning during and after COVID-19.

\section{METHOD}

This brief study aimed to measure undergraduate Psychology students' online learning readiness at a Portuguese university to derive implications for teaching practice. Our main research question was: Considering the four components of SOLR model, what are these students' self-perceived levels of online learning readiness? To this end, we have employed a quantitative methodology, resourcing to a structured online learning readiness scale which integrates the SOLR model.

\subsection{Participants}

The final sample consists of 77 undergraduate bachelors' in Psychology students from the same university. The majority of these are female $(90.9 \%)$ and only $7.8 \%$ are male. Participants are aged between 18 and 51 years-old $(M=21,17 ; \mathrm{SD}=4,81)$. Twenty six percent are first year students, $28,6 \%$ are second year students and $44,2 \%$ are third year student (the undergraduate bachelors' in Psychology course in Portugal consists of three years).

\subsection{Measures}

Data was collected using the Student Online Learning Readiness (SOLR) instrument [12], provided by the author with permission to use online. This questionnaire consists of 20 self-reported items, including five items for the measurement of social competencies with the instructor in online learning, five items for the measurement of social competencies with classmates in online learning, four items for the measurement of communication competencies in online learning, and six items for the measurement of technical competencies in online learning. The 20 SOLR survey items were measured on a 5 -point scale ( $1=$ Totally disagree, $2=$ Partially disagree, 3 $=$ No disagree, nor agree, $4=$ Partially agree, $5=$ Totally agree). For original version, Cronbach's alpha for internal consistency for each subscale was .882 for technical competencies, .823 for social competencies with classmates, .874 for social competencies with the instructor, and .871 for communication competencies, with sample size of 331 [12].

Since no available translated version to Portuguese was found, we requested the author permission to translate. Translation process followed these steps: (i) forward translation from English to Portuguese; (ii) back translation from Portuguese to English; (iii) comparison between the two translations and adjustments; (iv) request for a group of six students to fill the questionnaire and comment on possible unclear questions/mistakes; (v) final version. The changes introduced in the Portuguese version were the following: the insertion of teacher (tutor/teacher) because the word instructor would not be familiar to the participant students; the insertion of the word "do you feel" instead of "are you" in the item asking "How confident are you. .." because in Portuguese it makes more sense and the meaning is similar; in the item "Initiate discussions with the instructor" we added debates/discussions; in the item "Pay attention to other students' social actions" we changes the word actions for behaviors because it also is more understandable in the Portuguese language.

\subsection{Data collection procedures}

A survey was created, and the survey link were distributed by email to all bachelor students. The contact with the potential participants was mediated by administrative academic services. Informed consent was obtained from participants (at the beginning of the questionnaires) and from the faculty board. No compensation was provided, and participants were guaranteed full confidentiality. All questionnaires were anonymous. Questionnaires were completed by participants on an online version, accessed through a link, sent with the invitation letter. Data were collected between June and July of 2020 .

\subsection{Data analysis procedures}

The collected data was analysed quantitatively, using IBM SPSS Statistics 24. Descriptive statistics including mean score and standard deviation was mainly conducted for each subscale. The median for each item was verified.

\section{RESULTS}

As aforementioned, the Student Online Learning Readiness (SOLR) instrument is composed of four dimensions, covering technical 
Table 1: Descriptive statistics of each subscale of the student online learning readiness (SOLR) questionnaire

\begin{tabular}{lrrr}
\hline & Mean & SD & Min.-Máx. \\
Technical competencies & 3,81 &, 90 & $1-5$ \\
Social competencies with classmates & 3,17 & $1-5$ \\
Social competencies with the instructor & 3,39 &, 96 \\
Communication competencies & 3,56 & 1,04 \\
\hline
\end{tabular}

Table 2: Median for each item of the subscale Technical competencies

\begin{tabular}{ll}
\hline Items & Median \\
I have a sense of self-confidence in using computer technologies for specific tasks. & 4 \\
I am proficient in using a wide variety of computer technologies. & 4 \\
I feel comfortable using computers. & 4 \\
I can explain the benefits of using computer technologies in learning. & 4 \\
I am competent at integrating computer technologies into my learning & 4 \\
I am motivated to get more involved in learning activities when using computer technologies. & 3 \\
Total $(N=77)$ &
\end{tabular}

Table 3: Median for each item of the subscale Social competencies with the instructor

Items

Clearly ask my instructor questions.

Initiate discussions with the instructor.

Seek help from instructor when needed.

Timely inform the instructor when unexpected situations arise.

Express my opinions to instructor respectfully.

Total $(N=77)$

Table 4: Median for each item of the subscale Social competencies with classmates

\begin{tabular}{ll}
\hline Items & 3 \\
Develop friendships with my classmates. & 3 \\
Pay attention to other students' social actions. & 3 \\
Apply different social interaction skills depending on situations. & 3 \\
Initiate social interaction with classmates. & 4 \\
Socially interact with other students with respect. & \\
Total $(N=77)$ &
\end{tabular}

competencies, social competencies with classmates, social competencies with the instructor (taken in this study as the teacher), and communication competencies. In accordance with the different dimensions of the scale, the findings are presented in the tables.

Table 1 presents students' mean scores and standard deviations on the four subscales. As Table 1 indicates, all students' average scores relative to the different dimensions range from 3.17 to 3.81 on a 5 -point Likert-type rating scale, indicating that on average these online learners exhibited above-medium levels of readiness toward online learning.

Tables 2 to 5 present the median for each item of the questionnaire per subscale, written as in the original English version available in the article by Yu and Richardson (2015). We highlight here the item that have the lowest median, on the scale from 1 to 5: "I am motivated to get more involved in learning activities when using computer technologies."; "Clearly ask my instructor questions.; "Initiate discussions with the instructor."; "Seek help from instructor when needed"; "Develop friendships with my classmates."; "Pay attention to other students' social actions."; "Apply different social interaction skills depending on situations."; "Initiate social interaction with classmates.". From these items, students consider themselves less ready/they find to less frequently initiate actions to interact with the instructor/teachers, mostly to ask questions or request for help. Yet, most of all, students seem to have lower levels of readiness in the social dimension of online learning.

\section{DISCUSSION}

Considering the data presented, participants exhibited abovemedium levels of readiness toward online learning. In this study, students' mean scores in the four subscales are all higher than the 
Table 5: Median for each item of the subscale Communication competencies

Items

I am comfortable expressing my opinion in writing to others.

I am comfortable responding to other people's ideas.

I am able to express my opinion in writing so that others understand what I mean.

I give constructive and proactive feedback to others even when I disagree.

Total $(N=77)$

theoretical mean of 3, ranging from 3.17 to 3.81 on a 5-point Likert scale. In the current study, considering this sample of college students, they present the highest readiness in the subscale of technical skills, followed by communication competencies, and the lowest readiness in the subscales related to social competencies both with classmates and the instructor/teacher.

From the above results, we found that college students may be relatively confident in their computer/network skills (such as use a wide variety of technologies to learning activities), which are pre-requisite for online learning. Thus, these students were ready to immediate change to online lessons. However, individual differences must be considered as well as other relevant dimensions for effective learning, mainly social skills within the online learning environment [10].

The results of this study reveal that two readiness subscales need special attention from teachers and students so to be developed throughout the next semester of online/distance learning: social competencies with teacher and classmates. Teachers may need to help students maintain and develop social competences, especially for online learning contexts and in a context were physical distance is recommended. For example, teachers may need to pay attention to social needs of the diverse students, especially to those who seem to be more absent from lessons and intensify social activities during the semester to deepen social interaction. Option for group activities and hands-on activities to solve problems related to syllabus may be a way for doing it. Also, teachers may plan specific moments during lessons to give feedback to students and to ask for feedback about lessons. Intensify tutorial support may be needed. Moreover, specific moments for students to ask questions and request help, via written or oral form can be relevant, as to understand what are the underlying competencies for self-regulation learning which need to be promoted in the students so they know when they need help and how they ask for it. The relationship with classmates is relevant for students' learning, most of all when social face-to-face interactions are restricted. For this, it is important that organizational actions from the university can occur and contribute to the enhancement of social interaction between students in an online environment, both during class and off class.

\section{CONCLUSIONS}

While online learning is becoming an increasingly large part of higher education, especially in face of unpredictable events like university shutdown as result of COVID-19, it also brings some challenges to students and teachers. This study identifies specific needs related to students' readiness for online learning and also suggests what kinds of supports are needed for distance learners to be successful. Therefore, educators and administrators in higher education should pay more attention to their students' online learning readiness by looking at their social, communication, and technical competencies [10].

There were limitations regarding this study. One important limitation is related to the instrument. The SOLR instrument was developed to measure students' perceived competencies, not actual observed competencies. This kind of student self-assessment can be biased [10]. It is recommended to compare differences between students' perceived competencies and their effective performance. One other limitation is related to the sample, only from one single university and from a specific area, which is unrepresentative of college students. For future research, it is recommended that this study be repeated with students from multiple colleges or universities to overcome statistical sampling bias. Another recommendation is to compare student readiness between students enrolled in different modes of online learning (online vs. blended).

\section{REFERENCES}

[1] M. J. Sá and S. Serpa. 2020. The Global Crisis Brought about by SARS-CoV-2 and Its Impacts on Education: An Overview of the Portuguese Panorama. Science Insights Education Frontiers, 5(2), 525-530. https://doi.org/10.15354/sief.20.ar039

[2] OECD, PISA 2018 Database. https://www.oecd.org/pisa/data/2018database/

[3] OECD. 2020. Education Responses to Covid19: Embracing Digital Learning and Online Collaboration. Paris. https://read.oecd-ilibrary.org/view/?ref=120_1205448ksud7oaj2\&title=Education_responses_to_Covid-19_Embracing_digital_ learning_and_online_collaboration

[4] OECD. 2020. Learning Remotely When Schools Close: How Well Are Students and Schools Prepared? Insights from PISA. Paris. https://read.oecd-ilibrary.org/view/ ?ref=127_127063-iiwm328658\&title=Learning-remotely-when-schools-close

[5] M. Wajdi, I. Kuswandi, U. Faruq, Z. Zulhijra, K. Khairudin \& K. Khoiriyah. 2020. Education Policy Overcome Coronavirus, A Study of Indonesians. EDUTEC. Journal of Education And Technology, 3(2), 96-106. https://doi.org/10.29062/edu. v3i2.42

[6] K. J. Sund. 2020. Suggestions for Moving Teaching Rapidly Online in the Face of the Corona Crisis. Working Paper. Roskilde University.

[7] U. Verawardina, L. Asnur, A. L. Lubis, Y. Hendriyani, D. Ramadhani, I. P. Dewi, R. Darni, T.J. Betri, W. Susanti, and T. Sriwahyuni. 2020. Talent Development \& Excellence Reviewing Online Learning Facing the Covid-19 Outbreak. 12(3s), 385-392.

[8] T. Surma, and P. A. Kirschner. 2020. Technology Enhanced Distance Learning Should Not Forget How Learning Happens. Computers in Human Behavior, 110, 106390. https://doi.org/10.1016/j.chb.2020.106390

[9] X. Zhu, and J. Liu. 2020. Education in and After Covid-19: Immediate Responses and Long-Term Visions. Postdigital Science and Education. https://doi.org/10. 1007/s42438-020-00126-3

[10] T. Yu (2018). Examining Construct Validity of the Student Online Learning Readiness (SOLR) Instrument Using Confirmatory Factor Analysis. Online Learning, 22(4), 277-288. doi:10.24059/olj.v22i4.1297.

[11] M. Engin. 2017. Analysis of Students' Online Learning Readiness Based on Their Emotional Intelligence Level. Universal Journal of Educational Research 5(12A), 32-40, 2017 https://doi.org/10.13189/ujer.2017.051306

[12] T. Yu, and J. C. Richardson. 2015. An Exploratory Factor Analysis and Reliability Analysis of the Student Online Learning Readiness (SOLR) instrument. Online Learning, 19(5), 120-141. http://dx.doi.org/10.24059/olj.v19i5 